\title{
Introduction: Keywords for Children's Literature and Education
}

\author{
Lissa Paul \\ Guest Editor \\ Brock University \\ Philip Nel \\ Guest Editor \\ Kansas State University
}

In the introduction to his Keywords: A Vocabulary of Culture and Society (1976), Raymond Williams describes the strangeness of coming back to Cambridge in 1945 after four-and-a-half years fighting in the Second World War. He felt alienated, he explains, because everyone seemed to be speaking a different language (p.11). Out of his desire to make sense of a world at once strange and familiar, he composed Keywords, a cultural vocabulary to map meanings of words he had thought he'd known, but that he was suddenly experiencing as "being used in interesting or difficult ways" (p.14).

In the forty years since its original publication, Keywords has become a classic text for cultural studies. Though the word "keywords" itself has come to be shorthand for discussing a vocabulary related to social and cultural studies, the words under discussion have changed. When Bruce Burgett and Glenn Hendler published Keywords for American Cultural Studies with New York University Press in 2007, they were paying homage to Williams by mapping changes in the vocabulary of cultural studies. They were also almost inadvertently opening the way for an entire new series of books designed to map the vocabulary of cultural studies in a range of twenty-first century disciplines. New York University Press now includes in its catalogue Keywords for Children's Literature (2011), Asian American Studies (2015), Disability Studies (2015), Environmental Studies (2016), Media Studies (2017) and Latina/o Studies (2017).

Through the 2016-17 academic year, we-Phil and Lissa-were soliciting authors for our second, more international edition of Keywords for Children's Literature, co-edited with Nina Christensen and slated for publication by New York University Press in 2019. With the parameters we had outlined for the established authors we solicited so clearly in our minds, we both set "keywords" assignments for our students in our respective master's level classes. Lissa's assignment was for students in the winter 2017 session of EDUC 5P01: Introduction to Social and Cultural Contexts of Education: Developing a Critical Language, Phil's for English 703: Critical Approaches to Children's Literature in Spring 2017. In pedagogical terms, we had both decided to give our students "problembased learning" assignments, that is the tasks we assigned to our students closely resembled the ones we gave to established scholars. Phil and Lissa gave similar assignments to their students, though Lissa designated hers as keywords "for Education," and Phil "for Children's Literature." To avoid repetition, we have reproduced an edited version of Phil's assignment here and are granting permission to use with appropriate credit:

Brock Education Journal, 27(2), 2018 


\section{Assignment}

Write an entry for Keywords for Children's Literature. Your entry cannot be a word that is already in the book. It needs to be a keyword that the book has failed to include.

\section{Choosing a Word}

Choose a word that is crucial to the discussion of children's literature, but also that is contested or conflicted. As Raymond Williams wrote in his Keywords (1976, 1983), keywords "involve ideas and values," get used in "interesting or difficult ways" — and in different ways by different people. So, if you find that, in critical conversations, a particular word is getting used in different ways by different people, then that's a candidate for your keyword. If you're stuck, take a second look at the introduction to Keywords for Children's Literature.

\section{Writing the Essay}

Here is a version of the assignment Lissa Paul and I gave contributors to Keywords for Children's Literature (2011). Adopting, modifying, and expanding criteria from Bennett, Grossberg and Morris'New Keywords and Burgett and Hendler's Keywords for American Cultural Studies, we developed the following guidelines:

- Your definition should offer a scholarly account of the word's origins but should focus on a particular interpretation of the word's significance for the study of children's literature and culture. Please look at the relevant entry or entries from the Oxford English Dictionary, and (when possible) other relevant material such as entries from Williams' Keywords, New Keywords, Keywords for American Cultural Studies, and/or other related critical works. You can access the Oxford English Dictionary on-line via the databases at the library.

- In your very first paragraph, begin with a history of the keyword itself. From there, move into the critical controversies in which this keyword is enmeshed.

- To quote New Keywords' editors, your entry "should offer concrete examples of usage." Those examples should come from children's literature (primarily) but can certainly include children's culture. Your mandate is to focus on traditions in English, but we invite you to include non-English traditions if or when you can.

Paul and Nel (2018) 
Though the instructions resemble those given to contributors to the first edition of Keywords for Children's Literature, we did of course recognize that the students were at the beginnings of their academic careers and we judged their work accordingly. In addition, we want to note that since Lissa's students were encouraged to "think locally," there are specific references to school boards in the Niagara region, to provincial (Ontario) guidelines and to Canadian contexts.

Because Lissa asked her students to identify keywords associated with pedagogical discourse and the "social and cultural" contexts of the course, students addressed issues related to class, gender, age, ability, religion and race. Words under discussion in class included "innocence," multicultural," "race" and "liminality," among others from Keywords for Children's Literature, though the conversations expanded to include other critical terms such as "hegemony," and "ideology." All the theoretical discussions were set in conversation with works of children's literature in order to demonstrate the relationships between theory and practice. Throughout the term, Lissa was very pleased to find that the students used the experience of working with the essays they were reading to inform the essays they were writing.

Neither Phil nor Lissa were strict about essay length, but we aimed for around 1500 words because that was the word count we set for contributors to the second edition. Lissa's students, incidentally, initially thought that they would be able to manage the relatively short format with ease. That was before Lissa kept turning the drafts back for revision and insisting that the students bring the same professionalism to their essays as we expect from the authors writing for the book. As students began critiquing each other's work, they also began to develop higher expectations for each other than they would typically have been accustomed to in a classroom context.

Both of us used our first edition of Keywords for Children's Literature as a core text in our respective classes, and made donations to charity to offset the royalties (about a dollar) we receive for each book, Lissa to the Canadian Children's Book Centre and Phil to Reading is Fundamental. In assigning Keywords for Children's Literature we knew that because the students were going to be writing keywords essays for us they would attend closely to both the structure and content of the essays they were reading.

Throughout their courses Phil and Lissa invited students to be receptive to potential keywords. When class discussions began to circulate around a particular idea we (in our respective classes) would ask if that idea qualified as a keyword. In what different ways was the word being used? What ideas or values were at stake? Which literary texts might we discuss in such an essay? In Phil's course, all eighteen students were required to choose their keywords in the seventh week (Lissa's students had to choose sooner, by about the third week of their twelve-week course). In the twelfth week, Phil devoted one class day to workshopping the keywords papers: Each student brought in multiple copies of a draft, and, using a rubric, their fellow students evaluated the draft. (Having written a draft, several students also met with Phil to discuss the challenges they were facing.) Students then turned in and discussed their essays in class, during the final week. As there were only six students in Lissa's graduate class, some class time was given most weeks to discussions on the progress of the essays. Lissa also met with each student for individual tutorials.

Although we have arranged the essays written by students in both classes alphabetically, we are introducing them separately in the next two paragraphs because 
Lissa's students wrote keywords essays "for education," and Phil's students wrote keywords essays "for children's literature." The six essays written by Lissa's students speak eloquently to the cultural vocabulary of education in the twenty-first century, each essay lighting up murky depths below deceptively transparent surfaces of commonly used words. The essay on "Numeracy," by Miranda Kus, for instance, begins with the unexpected fact of the term's recent origin, in 1959, in a British educational policy document. Kus then plays out ways in which the interpretation of numeracy is contested by politicians and educators. Numeracy is a word not related to mathematics but to educational policy. In "Empathy," Jordan Palmer traces the word's origins in ideas of being able to feel or to respond to the feelings of others, then maps the way "empathy" moves towards something that is supposedly teachable through what is oddly described as "effortful control." Palmer then interrogates the question of whether or not teaching empathy implies domination and/or surveillance. Nigel Crosscombe's essay on "Innovation" begins with a discussion on the ways in which Google as well as other companies selling educational technologies now tie the word that once used to mean "novelty" to products educators are encouraged to buy. The fact that "innovation" appeared over two hundred times in the 2017 Canadian federal budget speaks to the (ominous) currency of the word. "Propaganda," as Katherine Fitzmaurice writes, is an example of another word whose meaning has become sinister over time. Though originally applied to religious indoctrination, when propaganda migrated to political doctrine, it came to refer to what "bad guys" did. In the context of education, Fitzmaurice identifies the irony in the fact that though education is supposed to teach children to think critically, and supposedly to resist propaganda, what children are taught in statemandated schools is also propaganda - that Democracy, for example, is good, and Communism is bad, if you are in North America.

There are also two neologisms in the "for education" essays: "Global Citizenship" by Evelina Osiadacz and "New Historicism" by Matt Hickling. In her essay on "Global Citizenship," Osiadacz traces the history of the two words, and explains how the term "citizen," which originally applied only to the local and specific, came to be linked to "global" with its associations in economic globalization. Hickling, in his essay on "New Historicism," explains the way the totalizing discourses of mid twentieth-century history (with the emphasis on events and technical achievement) morphed into new historicism (with attention on the impact events had on people). In educational terms, the shift is between the teaching of say, the "last spike" (the story of the national railroad linking the country) as a signal technological event in Canadian history, to teaching the story of the resistance of the Métis leader, Louis Riel. The six essays produced by Lissa's students stand as impressive in their mapping of educational keywords for the twenty-first century. Almost to their surprise, the students found the stings hiding in the buzzwords current in their day-to-day working lives in education.

As Phil's students are pursuing master's degrees in Literature, their seven essays are clearly centered in children's literature. In "Adaptation," Emily Nance shows how our tendency to privilege an original (as that against which to measure the new version) also assumes that there is an original, instead of many influences that inform a new work. Indeed, as she points out, some works complicate the very notion of a source text: Even in the first decade of its existence, Peter Pan circulated in multiple and competing variations (story for adults, playscript, novel for children, published play). As Nance 
suggests, children's literature's tradition of retelling stories — especially fairy tales further blurs boundaries between source and adapted version. In "Authenticity," Roxana Loza also addresses questions of the "true" version of a story, but shifts our focus to the role that authors and others play in shaping that narrative. If children's literature is alleged to be defined by its audience, then — Loza reminds us — not only do adult gatekeepers form a key part of that audience, but we must acknowledge the ways in which our embodied experiences expose us to different truths about the world in which we live. Can an author who is not a member of the community that her book strives to represent tell an authentic story about that community? Yet, as Loza notes, in striving to avoid stereotyping, the laudable goal of monitoring representation may have the unintended effect of perpetuating stereotypes by suggesting that there is a "true" identity for a particular group. A different look at what's appropriate in children's literature, Kathleen Wallace's essay considers how the oft-deployed (but poorly understood) term "appropriate" serves three distinct functions. First, it attempts to police the borders of childhood - a subject also pursued in Catherine Williams' essay. Second, it builds upon educators' research on what is "developmentally appropriate" for different phases of a young person's development. In so doing, it inadvertently reminds us that "child" is a capacious term, covering many ages and abilities: all children do not pass the same benchmarks at precisely the same time. Third, the term is inextricably intertwined with adult notions of morality.

In her "Adult" essay, Catherine Williams pursues that unacknowledged doppelgänger of childhood - adulthood, which is less childhood's alleged opposite than its secret twin. Citing Marah Gubar's kinship model, she notes that (quoting Gubar) "children and adults are separated by differences of degree, not kind." That difficult-to-define transition from childhood to adulthood is also a key concern of Corinne Matthews' essay on "Sexuality." As she points out, when young people "explore their sexuality," they are seen to have "disturbed the boundary between childhood and adulthood." Though (as Matthews shows us) there is such a thing as childhood sexuality, "an ideology of childhood innocence" threatens to silence its expression in works for children and young adults. Indeed, some adults' attempts to police even knowledge of sexuality (typically, in the service of "protecting" children) imposes an ignorance that places children at greater risk - to both misinformation and abuse. Pursuing the permeability of childhood's borders in another context, Cora Jaeger's “Animal" explores children's books' preference for animal characters, whether they aspire to humanize animalistic children, remind us humans that we too are animals, or (in racist children's literature) draw false distinctions between human people and non-human people. The unruly animal-child can also be an expression of children's agency — a subject pursued in M.E. Moore's "Fan." As Moore points out, engaging in a fan community can both grant children the power to reshape stories ("restorying") and risks interpellating them "into capitalist fan interactions." Like so many keywords for children's literature and education, "fan" exposes the many paradoxes of childhood. For instance, fannish behaviour is figured both as a manifestation of childish enthusiasm and as not for children, either because the young often lack capital to attend the convention or because many objects of fandom are considered "adult." And, yet, if children's literature and culture is defined by its audience, child fans' participation may, as Moore notes, grant scholars access to that audience. 
Both Phil and Lissa were sufficiently impressed by the essays written by our respective students in the early stages of their graduate careers that we wanted to provide them with the opportunity to see their class work find its way into a scholarly peerreviewed publication. Every essay was reviewed by two readers and we are particularly grateful to those who took the time to provide experienced feedback to our students. We also want to express our thanks to Katherine Fitzmaurice, Matt Hickling and Miranda Kus for their assistance in copy editing the final manuscript. They were funded by the Grad Fund of the Faculty of Education at Brock, to whom we also express our gratitude. And thanks to Dr. Dolana Mogadime, editor of Brock Education, for encouraging us to produce our special "Keywords" edition of the journal. In the end, we hope that the original work done by our students provides a clear demonstration of what is possible in a classroom assignment.

Whether a person is an established scholar or a student, writing a keywords essay is one of the most challenging and intellectually rewarding assignments she or he can undertake. By compelling us to look closely at a single term's many and conflicting permutations, writing one of these essays shows us how words can obscure what they purport to reveal. In teaching us how language can conceal complexity, the keywords essay can create a richer, more nuanced relationship not just with education and children's literature, but with discourse more generally. The process gives us what Williams calls "that extra edge of consciousness" (24), enabling us to better examine our own acculturation, and to develop our and our students' critical literacies. 


\section{References}

Adams, R, Reiss, B, \& Serlin, S. (2015). Keywords for disability studies. New York: New York UP.

Adamson, J, Gleason, W. A, \& Pellow, D. N. (2016). Keywords for environmental studies. New York: New York UP.

Burgett, B., \& Hendler, G. (2007) Keywords for American cultural studies. New York: New York UP.

Nel, P. \& Paul, L. (2011). Keywords for children's literature. New York: New York UP.

Oullette, L., \& Gray, J. (2017). Keywords for media studies. New York: New York UP.

Schlund-Vials, C, Trinh, L, \& Wong, K. S. (2015) Keywords for Asian American studies. New York: New York UP.

Vargas, D. R., Mirabal, N. R., \& La Fountain-Stokes, L. (2017). Keywords for Latina/o studies. New York: New York UP.

Williams, R. (1983) Keywords: A vocabulary of culture and Society. (Rev.ed). London: Harper Collins. 